\title{
FAKTOR RISIKO UMUR, GRAVIDA, STATUS GIZI DAN KEHAMILAN GANDA DENGAN KEJADIAN HIPEREMESIS GRAVIDARUM (STUDI KASUS KONTROL DI RSUD ACEH TAMIANG)
}

\author{
Mailinda Purwanti $^{1}$, Netty Etalia Brahmana ${ }^{2}$, Wisnu Hidayat ${ }^{3}$
}

\author{
${ }^{1}$ Progam Studi Magister Ilmu Kesehatan Masyarakat, Universitas Sari Mutiara Indonesia Medan \\ Email: meylindapurwanti@yahoo.com \\ ${ }^{2}$ Direktorat Pasca Sarjana Ilmu Kesehatan Masyarakat, Universitas Sari Mutiara Indonesia Medan \\ Email: brahmananetti@gmail.com \\ ${ }^{3}$ Direktorat Pasca Sarjana Ilmu Kesehatan Masyarakat, Universitas Sari Mutiara Indonesia Medan \\ Email :hrwisnu@yahoo.com
}

Masuk:24-08-2019, revisi: 08-11-2019, diterima untuk diterbitkan: 18-11-2019

\begin{abstract}
ABSTRAK
Hiperemesis gravidarum adalah mual muntah yang terjadi sampai umur kehamilan 20 minggu, muntah begitu hebat dimana segala apa yang dimakan dan diminum dimuntahkan sehingga mempengaruhi keadaaan umum dan pekerjaan sehari-hari, berat badan menurun, dehidrasi dan terdapat aseton dalam urin bukan karena penyakit seperti appendisitis, pielitis, dan sebagainya.Penelitian ini bertujuan untuk mengetahui faktor risiko umur, gravida, status gizi dah kehamilan ganda terhadap kejadian hiperemesis gravidarum (studi kasus control di RSUD Aceh Tamiang Tahun 2018). Penelitian ini di laksanakan bulan Januari 2018-Desember 2018. Jenis penelitian yang digunakan adalah penelitian observasi analitik dengan pendekatan casecontrol. Populasi dalam penelitian ini adalah seluruh ibu hamil dengan diagnosa hiperemesis gravidarum yang di rawat di ruang kebidanan RSUD Aceh Tamiang sejak januari-desember 2018 yang diperoleh dari data rekam medik rumah sakit tersebut sebanyak 94 orang. Sampel dalam penelitian ini terbagi 2 yaitu sampel kasus sebanyak 94 orang dan sampel kontrol sebanyak 94 orang. Berdasarkan uji statistik diperoleh hasil ada hubungan faktor umur dengan kejadian hiperemesis gravidarum dengan nilai $\rho$ value $=0,000$. Nilai $p=0,000$ yang lebih kecil dari $\alpha=0,05$, Ada hubungan faktor gravida dengan kejadian hiperemesis gravidarum dengan nilai $\rho$ value $=0,000$. Nilai $p=0,000$ yang lebih kecil dari $\alpha=0,05$, Ada hubungan faktor status gizi dengan kejadian hiperemesis gravidarum dengan nilai $\rho$ value $=0,001$. Nilai $p=0,001$ yang lebih kecil dari $\alpha=0,05$ dan Tidak ada hubungan faktor kehamilan ganda dengan hiperemesis gravidarum dengan nilai $\rho$ value $=0,274$. Nilai $p=0,274$ yang lebih besar dari $\alpha=0,05$ Di RSUD Aceh Tamiang. Peneliti menyarankan agar penelitian ini dapat menjadi informasi dalam pemberian pelayanan yang maksimal dalam fasilitas kesehatan dan sumber memperluas wawasan bagi pendidikan.
\end{abstract}

Kata Kunci : Hiperemesis Gravidarum; Umur; Gravida; Status Gizi; Kehamilan Ganda

\section{ABSTRACT}

Hyperemesis gravidarum is nausea, vomiting that occurs until 20 weeks' gestation, vomiting is so severe that everything that is eaten and drunk is vomited so that it affects general circumstances and daily work, weight loss, dehydration and acetone in the urine not due to diseases such as appendicitis, pielitis, and so on. This study aims to determine the risk factors for age, gravida, nutritional status and multiple pregnancy against the incidence of hyperemesis gravidarum (case control study in Aceh Tamiang District Hospital 2018). This research was conducted in January 2018-December 2018. The type of research used was analytic observational research with a case-control approach. The population in this study were all pregnant women with a diagnosis of hyperemesis gravidarum treated in the obstetric room of Aceh Tamiang Regional Hospital since January-December 2018 obtained from the hospital's medical record data of 94 people. The sample in this study was divided into two, namely 94 case samples and 94 control samples. Based on statistical tests, the results show that there is a relationship between age and hyperemesis gravidarum with $\rho$ value $=0,000$. Value of $p=0,000$ which is smaller than $\alpha=0.05$, there is a relationship between gravida factor and the occurrence of hyperemesis gravidarum with $\rho$ value $=0,000$. Value $p=0,000$ which is smaller than $\alpha=$ 0.05 , there is a relationship between nutritional status factors and the incidence of hyperemesis gravidarum with $\rho$ value $=$ 0.001. $P$ value $=0.001$ which is smaller than $\alpha=0.05$ and there is no relationship between multiple pregnancy factors and hyperemesis gravidarum with a value of value $=0.274$. Value of $p=0.274$ which is greater than $\alpha=0.05$ in Aceh Tamiang District Hospital. The researcher suggests that this research can be information in providing maximum services in health facilities and sources of broadening insight for education.

Keywords: Hyperemesis Gravidarum; Age; Gravida; Nutritional status; Double Pregnancy 


\section{PENDAHULUAN}

\section{LATAR BELAKANG}

Kehamilan merupakan suatu keadaan fisiologis yang menjadi dambaan setiap pasangan suami istri. Setiap kehamilan diharapkan adalah lahirnya bayi yang sehat dan sempurna secara jasmaniah dengan berat badan yang cukup. Salah satu komplikasi kehamilan yang mempengaruhi status kesehatan ibu dan tumbuh kembang janin adalah hiperemesis gravidarum dimana kejadian ini dapat dideteksi dan dicegah pada masa kehamilan, mual, dan muntah merupakan gangguan yang paling sering dijumpai pada kehamilan trimester I sekitar 60\%-80\% pada primigravida dan 40\%-60\% pada multigravida (Andriani, M 2016).

Mual dan muntah merupakan gangguan yang paling sering dijumpai pada kehamilan muda dan dikeluhkan oleh 50-70\% wanita hamil dalam 16 minggu pertama. Kurang lebih $66 \%$ wanita hamil trimester pertama akan mengalami mual, dan $44 \%$ mengalami muntah. Angka kejadian hiperemesis gravidarum 4:1000 kehamilan, sindrom ini ditandai dengan muntah yang sering, penurunan berat badan, dehidrasi, asidosis karena kelaparan yang ditandai dengan ketonuria, alkalosis karena penurun asam HCL lambung dan hipoglikemi( Efendi Jusuf,Dkk 2017).

Akibat yang ditimbulkan dari hiperemesis gravidarum adalah mual dan muntah yang biasanya menyebabkan wanita hamil mengalami penurunan berat badan $(<15,4 \mathrm{lb}$ atau $7 \mathrm{~kg})$ dengan meningkatnya risiko bayi berat lahir rendah, persalinan prematur, dapat meningkatkan kejadian gangguan pertumbuhan janin dalam rahim atau PJT (IUGR) (Ogunyemi D, et al, 2017; Jusuf CE，2016).

Menurut World Health Organiztion (WHO) pada tahun 2015 jumlah kejadian emesis gravidarum mencapai 12,5 \% dari jumlah kehamilan di dunia, . Kunjungan pemeriksaan kehamilan ibu hamil di Indonesia diperoleh data ibu dengan hiperemesis gravidarum mencapai 14,8\% dari seluruh kehamilan. Untuk prevalensi hiperemesis gravidarum terjadi diantara $0,8 \%$ dan 3,2\% (Vikanes A, et al, 2013). Studi lain mendapatkan bahwa prevalensi hiperemesis gravidarum di Norwegia 1,1\% pada 814 pasien dari 71.468 pasien (Vikanes A, et al, 2013). Dan prevalensi hiperemesis gravidarum di Amerika Serikat $0,5 \%$ sampai $2 \%$ dengan variasi insiden yang didapatkan dari berbagai kriteria diagnostik dan variasi suku (Khan $\mathrm{F}$, et al, 2016).

Insiden yang menggambarkan mual dan muntah sebagai ganguan medis yang sering terjadi selama kehamilan. angka mual antara $70 \%$ dan $85 \%$ dengan sekitar setengah dari presentase ini mengalami muntah. Keadaan Hiperemesis Gravidarum yang sangat fatologis jauh lebih jarang terjadi dibandingkan mual muntah secara logis. (Kemenkes RI, 2016). Angka kematian ibu (AKI) di aceh masih cukup tinggi yaitu 143 per 100.000 kelahiran hidup. Dan angka kematian bayi (AKB) sebanyak 10 per 1.000 kelahiran hidup. Jumlah kematian ibu di provinsi aceh yang disebabkan oleh hiperemesis gravidarum sebanyak 1 orang $(0,5 \%)$, ibu bersalin sebesar 25\% dan ibu nifas sebesar 52\% (Dinas kesehatan Aceh 2018).

Berdasarkan data tahun 2017 dan 2018 yang diperoleh dari ruang rawat inap kebidanan di RSUD Aceh Tamiang, ibu hamil yang mengalami hiperemesis gravidarum pada tahun 2017 sebanyak 78 dari 682 ibu hamil, dan pada tahun $2018 \mathrm{ibu}$ hamil yang mengalami hiperemesis gravidarum sebanyak 94 dari 765 ibu hamil. Dari data yang penulis uraikan penulis menyimpulkan setiap tahunnya kasus hiperemesis gravidarum di RSUD Aceh Tamiang mengalami peningkatan. Maka dari itu penulis tertarik untuk melakukan penelitian dengan judul " faktor risiko umur, status gravida, status gizi dan kehamilan ganda dengan kejadian hiperemesis gravidarum (Studi Kasus Kontrol Di RSUD Aceh Tamiang)" 


\section{METODE PENELITIAN}

Jenis penelitian yang digunakan adalah penelitian observasi analitik dengan pendekatan casecontrol di lakukan di RSUD Aceh Tamiang Dengan menggunakan Data Skunder. Populasi dalam penelitian ini adalah seluruh ibu hamil dengan diagnosa hiperemesis gravidarum yang di rawat di ruang kebidanan RSUD Aceh Tamiang sejak januari-desember 2018 yang diperoleh dari data rekam medik rumah sakit tersebut sebanyak 94 orang. Sampel dalam penelitian ini terbagi 2 yaitu sampel kasus sebanyak 94 orang dan sampel kontrol sebanyak 94 orang. Teknik pengambilan sampel pada penelitian ini adalah total sampling. Cara pengumpulan data pada penelitian ini adalah studi dokumentasi, yaitu metode pengumpulan data yang tidak ditujukan langsung kepada subjek penelitian. Dokumen yang di gunakan dalam penelitian ini adalah dokumen skunder, yaitu dokumen yang ditulis berdaskan oleh catatan rekam medik.

\section{HASIL DAN PEMBAHASAN}

Hasil analisis penelitian ini disajikan dalam Analisis Univariat, Analisis Bivariat dan Analisis Multivariat

\section{Analisis Univariat}

Tabel. 1. Distribusi Frekuensi Faktor Risiko Umur Ibu Hamil Dengan Kejadian Hiperemesis Gravidarum di RSUD Aceh Tamiang

\begin{tabular}{ccrrrr}
\hline \multirow{2}{*}{ No } & \multirow{2}{*}{ Faktor Umur Ibu } & \multicolumn{3}{c}{ Kejadian Hiperemesis Gravidarum } \\
\cline { 3 - 6 } & & \multicolumn{3}{c}{ Kasus } & \multicolumn{2}{c}{ Kontrol } \\
\cline { 3 - 6 } & & F & \% & F & \% \\
\hline 1 & $<20$ dan $>35$ & 48 & 51,1 & 22 & 23,4 \\
2 & $20-35$ & 46 & 48,9 & 72 & 76,6 \\
\hline & Total & $\mathbf{9 4}$ & $\mathbf{1 0 0}$ & $\mathbf{9 4}$ & $\mathbf{1 0 0}$ \\
\hline
\end{tabular}

Berdasarkan table 1. di atas diperoleh data bahwa pada kelompok kasus, hiperemesis gravidarum lebih banyak terjadi pada usia $<20$ dan $>35$ tahun yaitu sebesar $51,1 \%$ (48 orang) dibandingkan dengan usia 20-35 tahun yaitu 48,9\% (46 orang). Sedangkan pada kelompok kontrol (yang tidak mengalami hiperemesis gravidarum) paling banyak ditemukan pada usia 20-35 tahun yaitu sebesar $76,6 \%$ (72 orang) dibandingkan pada usia $<20$ dan $>35$ tahun yaitu sebesar $23,4 \%$ (22 orang).

Tabel 2. Distribusi Frekuensi Faktor Risiko Gravida Ibu Hamil Dengan Kejadian Hiperemesis Gravidarum di RSUD Aceh Tamiang

\begin{tabular}{cccccc}
\hline \multirow{2}{*}{ No } & \multirow{2}{*}{ Faktor } & \multicolumn{3}{c}{ Kejadian Hiperemesis Gravidarum } \\
\cline { 3 - 6 } & Gravida & \multicolumn{3}{c}{ Kasus } & \multicolumn{3}{c}{ Kontrol } \\
\cline { 3 - 6 } & & F & \% & F & \% \\
\hline 1 & Primigravida & 65 & 69,1 & 37 & 39,4 \\
2 & Multigravida & 29 & 30,9 & 57 & 60,6 \\
\hline & Total & $\mathbf{9 4}$ & $\mathbf{1 0 0}$ & $\mathbf{9 4}$ & $\mathbf{1 0 0}$ \\
\hline
\end{tabular}

Berdasarkan tabel 2. di atas diperoleh data bahwa pada kelompok kasus, hiperemesis gravidarum lebih banyak terjadi pada ibu primigravida yaitu sebesar $69,1 \%$ (65 orang) dibandingkan dengan ibu multigravida sebesar 30,9\% (29 orang). Sedangkan pada kelompok kontrol (yang tidak mengalami hiperemesis gravidarum) paling banyak ditemukan pada ibu multigravida yaitu sebesar 60,6\% (57 orang) dibandingkan pada ibu primigravida yaitu sebesar 39,4\% (37 orang). 
Tabel 3. Distribusi Frekuensi Faktor Risiko Status Gizi Ibu Hamil Dengan Kejadian Hiperemesis Gravidarum di RSUD Aceh Tamiang

\begin{tabular}{cccccc}
\hline & & \multicolumn{3}{c}{ Kejadian Hiperemesis Gravidarum } \\
\cline { 3 - 6 } No & \multirow{2}{*}{ Faktor Status Gizi } & \multicolumn{3}{c}{ Kasus } & \multicolumn{2}{c}{ Kontrol } \\
\cline { 3 - 6 } & & F & \% & F & \% \\
\hline 1 & Gizi Kurang & 50 & 53,2 & 27 & 28,7 \\
2 & Gizi Baik & 44 & 46,8 & 67 & 71,3 \\
\hline Total & $\mathbf{9 4}$ & $\mathbf{1 0 0}$ & $\mathbf{9 4}$ & $\mathbf{1 0 0}$ \\
\hline
\end{tabular}

Berdasarkan tabel. 3 di atas diperoleh data bahwa pada kelompok kasus, hiperemesis gravidarum lebih banyak terjadi pada ibu yang memiliki status gizi kurang (LILA $<23,5 \mathrm{~cm}$ )yaitu sebesar $53,2 \%$ (50 orang) dibandingkan dengan ibu yang memiliki status gizi baik sebesar $46,8 \%$ (44 orang). Sedangkan pada kelompok kontrol (yang tidak mengalami hiperemesis gravidarum) paling banyak ditemukan pada ibu yang memiliki status gizi (LILA >23,5) baik yaitu sebesar $71,3 \%$ (67 orang) dibandigkan pada ibu yang memiliki status gizi kurang yaitu sebesar $28,7 \%$ (27 orang).

Tabel.4 Distribusi Frekuensi Faktor Risiko Kehamilan Ganda Ibu Hamil Dengan Kejadian Hiperemesis Gravidarum di RSUD Aceh Tamiang

\begin{tabular}{|c|c|c|c|c|c|}
\hline \multirow{3}{*}{ No } & \multirow{3}{*}{$\begin{array}{c}\text { Faktor Kehamilan } \\
\text { Ganda }\end{array}$} & \multicolumn{4}{|c|}{ Kejadian Hiperemesis Gravidarum } \\
\hline & & \multicolumn{2}{|c|}{ Kasus } & \multicolumn{2}{|c|}{ Kontrol } \\
\hline & & $\mathbf{F}$ & $\%$ & $\mathbf{F}$ & $\%$ \\
\hline 1 & $\mathrm{Ya}$ & 15 & 16,0 & 9 & 9,6 \\
\hline 2 & Tidak & 79 & 84,0 & 85 & 90,4 \\
\hline & Total & 94 & 100 & 94 & 100 \\
\hline
\end{tabular}

Berdasarkan tabel 4. di atas diperoleh data bahwa pada kelompok kasus, hiperemesis gravidarum lebih banyak terjadi pada ibu yang tidak mengalami kehamilan ganda yaitu sebesar 84,0\% (79 orang) dibandingkan dengan ibu yang mengalami kehamilan ganda sebesar 16,0\% (15 orang). Begitu juga pada kelompok kontrol (yang tidak mengalami hiperemesis gravidarum) paling banyak ditemukan pada ibu yang tidak mengalami kehamilan ganda yaitu sebesar 90,4\% (85 orang) dibandigkan pada ibu yang mengalmi kehamilan ganda yaitu sebesar 9,6\% (9 orang).

\section{Analisis Bivariat}

Tabel 5.Distribusi Proporsi Faktor Risiko Umur Ibu Hamil Dengan Kejadian Hiperemesis Gravidarum di RSUD Aceh Tamiang

\begin{tabular}{|c|c|c|c|c|c|c|c|c|c|}
\hline \multirow{3}{*}{ No } & \multirow{3}{*}{$\begin{array}{l}\text { Umur Ibu } \\
\text { (Tahun) }\end{array}$} & \multicolumn{4}{|c|}{$\begin{array}{c}\text { Kejadian Hiperemesis } \\
\text { Gravidarum }\end{array}$} & \multirow{2}{*}{\multicolumn{2}{|c|}{ Total }} & \multirow{3}{*}{ p value } & \multirow{3}{*}{$\begin{array}{c}\text { OR } \\
(\mathrm{CI}=95 \%)\end{array}$} \\
\hline & & \multicolumn{2}{|c|}{ Kasus } & \multicolumn{2}{|c|}{ Kontrol } & & & & \\
\hline & & $\mathrm{f}$ & $\%$ & $f$ & $\%$ & $\mathrm{f}$ & $\%$ & & \\
\hline 1 & $<20$ dan $>25$ & 4 & 51,1 & 22 & 23,4 & 70 & 37,2 & \multirow{3}{*}{0,000} & \multirow{3}{*}{$\begin{array}{c}3,415 \\
(1,827- \\
6,385)\end{array}$} \\
\hline \multirow[t]{2}{*}{2} & $20-35$ & $\begin{array}{l}8 \\
4 \\
6 \\
\end{array}$ & 48,9 & 72 & 76,6 & 118 & 62,8 & & \\
\hline & Total & 94 & 100 & 94 & 100 & 188 & 100,0 & & \\
\hline
\end{tabular}


Berdasarkan Tabel 5. diperoleh data bahwa kejadian hiperemesis gravidarum pada kelompok kasus lebih banyak terjadi pada usia $<20$ dan $>35$ tahun yaitu sebesar 51,1\% (48 orang) dibandingkan dengan usia 20-35 tahun yaitu 48,9\% (46 orang). Sedangkan pada kelompok kontrol (yang tidak mengalami hiperemesis gravidarum) paling banyak ditemukan pada usia 2035 tahun yaitu sebesar $76,6 \%$ (72 orang) dibandigkan pada usia $<20$ dan $>35$ tahun yaitu sebesar 23,4\% (22 orang). Tingkat risiko antara faktor umur dengan kejadian hiperemesis gravidarum ditunjukkan dengan nilai OR sebesar 3,415, sehingga dapat dinyatakan bahwa umur ibu $<20$ dan >35 tahun, cenderung mengalami hiperemesis gravidarum 3,4 kali lebih besar dibandingkan umur ibu yang berumur 20-35 tahun.

Tabel 6. Distribusi Proporsi Faktor Risiko Gravida Ibu Hamil Dengan Kejadian Hiperemesis Gravidarum di RSUD Aceh Tamiang

\begin{tabular}{|c|c|c|c|c|c|c|c|c|c|}
\hline \multirow{3}{*}{ No } & \multirow{3}{*}{ Gravida } & \multicolumn{4}{|c|}{$\begin{array}{c}\text { Kejadian Hiperemesis } \\
\text { Gravidarum }\end{array}$} & \multirow{2}{*}{\multicolumn{2}{|c|}{ Total }} & \multirow{3}{*}{ p value } & \multirow{3}{*}{$\begin{array}{c}\text { OR } \\
(\mathbf{C I}=95 \%)\end{array}$} \\
\hline & & \multicolumn{2}{|c|}{ Kasus } & \multicolumn{2}{|c|}{ Kontrol } & & & & \\
\hline & & $\mathrm{F}$ & $\%$ & $\mathrm{~F}$ & $\%$ & $\mathrm{f}$ & $\%$ & & \\
\hline 1 & Primigravida & 65 & 69,1 & 37 & 39,4 & 102 & 54,3 & \multirow{3}{*}{0,000} & \multirow{3}{*}{$\begin{array}{c}3,453 \\
(1,891-6,306)\end{array}$} \\
\hline 2 & Multigravida & 29 & 30,9 & 57 & 60,6 & 86 & 45,7 & & \\
\hline & Total & 94 & 100,0 & 94 & 100,0 & 188 & 100,0 & & \\
\hline
\end{tabular}

Berdasarkan tabel 6. diperoleh data bahwa kejadian hiperemesis gravidarum pada kelompok kasus lebih banyak terjadi pada ibu primigravida yaitu sebesar 69,1\% (65 orang) dibandingkan dengan ibu multigravida sebesar 30,9\% (29 orang). Sedangkan pada kelompok kontrol (yang tidak mengalami hiperemesis gravidarum) paling banyak ditemukan pada ibu multigravida yaitu sebesar 60,6\% (57 orang) dibandigkan pada ibu primigravida yaitu sebesar 39,4\% (37 orang).Tingkat risiko antara faktor gravida dengan kejadian hiperemesis gravidarum ditunjukkan dengan nilai OR sebesar 3,453, sehingga dapat dinyatakan bahwa ibu dengan primigravida, cenderung mengalami hiperemesis gravidarum 3,4 kali lebih besar dibandingkan ibu yang memiliki multigravida.

Tabel. 7 Distribusi Proporsi Faktor Risiko Status Gizi Ibu Hamil Dengan Kejadian Hiperemesis Gravidarum di RSUD Aceh Tamiang

\begin{tabular}{|c|c|c|c|c|c|c|c|c|c|}
\hline \multirow{3}{*}{ No } & \multirow{3}{*}{ Status Gizi } & \multicolumn{4}{|c|}{$\begin{array}{c}\text { Kejadian Hiperemesis } \\
\text { Gravidarum }\end{array}$} & \multirow{2}{*}{\multicolumn{2}{|c|}{ Total }} & \multirow{3}{*}{ p value } & \multirow{3}{*}{$\begin{array}{c}\text { OR } \\
(\mathbf{C I}=95 \%)\end{array}$} \\
\hline & & \multicolumn{2}{|c|}{ Kasus } & \multicolumn{2}{|c|}{ Kontrol } & & & & \\
\hline & & $f$ & $\%$ & $f$ & $\%$ & $f$ & $\%$ & & \\
\hline 1 & Gizi Kurang & 50 & 53,2 & 27 & 28,7 & 77 & 41,0 & \multirow{3}{*}{0,001} & \multirow{3}{*}{$\begin{array}{c}2,820 \\
(1,543-5,154)\end{array}$} \\
\hline 2 & Gizi Baik & 44 & 46,8 & 67 & 71,3 & 111 & 59,0 & & \\
\hline & Total & 94 & 100,0 & 94 & 100,0 & 188 & 100,0 & & \\
\hline
\end{tabular}

Berdasarkan tabel 7. di atas diperoleh data bahwa kejadian hiperemesis gravidarum lebih banyak terjadi pada ibu yang memiliki status gizi kurang (LILA $<23,5 \mathrm{~cm}$ ) yaitu sebesar 53,2\% (50 orang) dibandingkan dengan ibu yang memiliki status gizi baik (LILA >23,5) sebesar 46,8\% (44 orang). Sedangkan pada kelompok kontrol (yang tidak mengalami hiperemesis gravidarum) paling banyak ditemukan pada ibu yang memiliki status gizi baik yaitu sebesar 71,3\% (67 orang) dibandigkan pada ibu yang memiliki status gizi kurang yaitu sebesar 28,7\% (27 orang).Tingkat risiko antara faktor status gizi dengan kejadian hiperemesis gravidarum ditunjukkan dengan nilai 
OR sebesar 2,820, sehingga dapat dinyatakan bahwa ibu dengan status gizi kurang, cenderung mengalami hiperemesis gravidarum 2,8 kali lebih besar dibandingkan ibu yang memiliki status gizi baik.

Tabel 8. Distribusi Proporsi faktor risiko kehamilan ganda ibu hamil dengan kejadian hiperemesis gravidarum di RSUD Aceh Tamiang

\begin{tabular}{|c|c|c|c|c|c|c|c|c|c|}
\hline \multirow{3}{*}{ No } & \multirow{3}{*}{$\begin{array}{c}\text { Kehamilan } \\
\text { Ganda }\end{array}$} & \multicolumn{4}{|c|}{$\begin{array}{c}\text { Kejadian Hiperemesis } \\
\text { Gravidarum }\end{array}$} & \multirow{2}{*}{\multicolumn{2}{|c|}{ Total }} & \multirow{3}{*}{ p value } & \multirow{3}{*}{$\begin{array}{c}\text { OR } \\
(\mathrm{CI}=95 \%)\end{array}$} \\
\hline & & \multicolumn{2}{|c|}{ Kasus } & \multicolumn{2}{|c|}{ Kontrol } & & & & \\
\hline & & $\mathrm{f}$ & $\%$ & $f$ & $\%$ & $f$ & $\%$ & & \\
\hline 1 & Ya & 15 & 16,0 & 9 & 9,6 & 24 & 12,8 & \multirow{3}{*}{0,274} & \multirow{3}{*}{$\begin{array}{c}1,793 \\
(0,743-4,329)\end{array}$} \\
\hline 2 & Tidak & 79 & 84,0 & 85 & 90,4 & 164 & 87,2 & & \\
\hline & Total & 94 & 100,0 & 94 & 100,0 & 188 & 100,0 & & \\
\hline
\end{tabular}

Berdasarkan tabel 8. diperoleh data bahwa kejadian hiperemesis gravidarum lebih banyak terjadi pada ibu yang tidak mengalami kehamilan ganda yaitu sebesar 84,0\% (79 orang) dibandingkan dengan ibu yang mengalami kehamilan ganda sebesar 16,0\% (15 orang). Begitu juga pada kelompok kontrol (yang tidak mengalami hiperemesis gravidarum) paling banyak ditemukan pada ibu yang tidak mengalami kehamilan ganda yaitu sebesar 90,4\% (85 orang) dibandigkan pada ibu yang mengalmi kehamilan ganda yaitu sebesar 9,6\% (9 orang). Tingkat risiko antara faktor kehamilan ganda dengan kejadian hiperemesis gravidarum di tunjukkan dengan nilai OR sebesar 1,793, sehingga dapat di nyatakan bahwa ibu yang tidak mengalami kehamilan ganda, cenderung mengalami hiperemesis gravidarum 1,7 kali lebih besar dibandingkan ibu yang mengalami kehamilan ganda.

Berdasarkan hasil uji regresi logistik ternyata semua variabel dalam model mempunyai $\mathrm{p}$ value < 0,05 berarti variabel umur dan gravida berhubungan secara bermakna terhadap kejadian hiperemesis gravidarum. Dilihat dari nilai $\operatorname{Exp}(B)$ atau OR pada faktor umur (Exp: 2,738), dan gravida (exp: 2,825). Maka dapat disimpulkan bahwa faktor gravida adalah faktor risiko yang paling dominan terhadap kejadian hiperemesis gravidarum.

Faktor gravida merupakan faktor yang paling mempengaruhi kejadian hiperemesis gravidarum, hal ini disebabkan hiperemesis gravidarum lebih sering dialami oleh primigravida dari pada multigravida, hal ini berhubungan dengan tingkat kestresan dan usia ibu saat mengalami kehamilan pertama. Pada ibu dengan primigravida, faktor psikologik memegang peranan penting pada penyakit ini, takut terhadap kehamilan dan persalinan, takut terhadap tanggung jawab sebagai seorang ibu dapat menyebabkan konflik mental yang dapat memperberat mual dan muntah sebagai ekspresi tidak sadar terhadap keengganan menjadi hamil atau sebagai pelarian kesukaran hidup (Nining, 2009).

Hasil penelitian ini sesuai dengan pendapat Winkjosastro (2010) yang mengungkapkan bahwa ibu primigravida belum mampu beradaptasi terhadap hormon estrogen dan khorionik gonadotropin. Peningkatan hormon ini membuat kadar asam lambung meningkat, hingga muncullah keluhan rasa mual. Keluhan ini biasanya muncul di pagi hari saat perut ibu dalam keadaan kosong dan terjadi peningkatan asam lambung.

Hasil penelitian ini sesuai dengan Penelitian Triana Indriani dengan judul faktor-faktor yang berhubungan dengan kejadian hiperemesis gravidarum di RSUD DR. Drajat Prawiranegara 
Kabupten serang tahun 2017 . Hasil analisis menunjukan bahwa dari 400 ibu hamil primigravida yang mengalami hiperemesis gravidarum sebanyak 203 orang $(87,1 \%)$ sedangkan pada primigravida yang tidak mengalami hiperemesis gravidarum sebanyak 30 orang $(12,9 \%)$. Dari 400 ibu hamil multigravida sebanyak 35 orang (21\%) mengalami hiperemesis gravidarum, sedangkan pada multigravida yang tidak mengalami hiperemesis gravidarum sebanyak 132 orang (79,0\%). Berdasarkan hasil uji statistik chi square di atas didapatkan $P$ Value $=0,000$. Nilai $\mathrm{P}<$ 0,05 dengan nilai $\mathrm{OR}=25,52$. Pada ibu hamil primigravida faktor psikologik memegang peranan penting pada penyakit ini, takut terhadap kehamilan dan persalinan, takut terhadap tanggung jawab sebagai seorang ibu dapat menyebabkan konflik mental yang dapat memperberat mual dan muntah sebagai ekspresi tidak sadar terhadap keengganan menjadi hamil atau sebagai pelarian kesukaran hidup.

\section{KESIMPULAN DAN SARAN}

Berdasarkan hasil pemelitian di RSUD Aceh Tamiang didapat hasil ada hubungan umur, gravida dan status gizi dengan kejadian hiperemesis gravidarum dan tidak ada hubungan status gizi dengan kejadian hiperemesis gravidarum. Faktor risiko yang paling dominan terhadap kejadian hiperemesis gravidarum di RSUD Aceh Tamiang adalah faktor gravida. Hasil tersebut didukung dengan data penelitian yang didapatkan bahwa sebagian besar sampel adalah primigravida. Adapun Saran Bagi RSUD Aceh Tamiang Diharapkan penelitian ini dapat digunakan oleh tim PKRS( Promosi Kesehatan Rumah Sakit) sebagai bahan untuk mengevaluasi pelayanan kepada Ibu hamil yang mengalami Hiperemesis Gravidarum. Peningkatan pelayanan dapat diwujudkan dengan mengadakan kelas ibu hamil yang berisi tentang pengetahuan ibu tentang hiperemesis gravidarum dalam kelas ibu hamil tidak hanya mendengaran penyuluhan saja melainkan di isi dengan sharing kesesama ibu hamil dan petugas kesehatan agar ibu hamil dapat mendapatkan solusi dari apa yang dirasakannya.

\section{Ucapan Terimakasih}

Penulis mengucapkan terimkasih kepada Direktur RSUD Aceh Tamiang yang telah memberikan izin dan memberikan dukungan terhadap penelitian ini.

\section{REFERENSI}

Adriani, M. dan Wirjatmadi, B. (2016), Peranan Gizi dalam Siklus Kehidupan. Jakarta: Kencana.

Dinkes Provinsi Aceh (2018), Kasus Hiperemesis Gravidarum. Dinas Kesehatan Provinsi Aceh. Kemenkes RI (2010),Hiperemeis Gravidarum. Dinas kesehatan RI Jakarta

Kemenkes RI (2016),Hiperemeis Gravidarum. Dinas kesehatan RI Jakarta

Khan F. Hyperemesis Gravidarum in Emergency Medicine. In: MedScape; 2016

Nining (2009). Hiperemesis Gravidarum. http:www.kesehatanreproduksi-wanita.com

Ogunyemi, D.A. (2017). Hyperemesis Gravidarum. In: MedScape

Triana indrayani (2017) faktor-faktor yang Berhubungan dengan Kejadian Hiperemesis Gravidarum pada Ibu Hamil Di RSUD DR. Drajat Prawiranegara Kabupaten Serang. “Jurnal akademi Keperawatan Husada Karya Jaya”, Vol:4, no:1, Maret 201, ISSN 2442$501 X$.

Yusuf, Efendi. (2017). Obstetri Patologi. Bandung: EGC

Wiknjosastro. (2010). Buku Panduan Praktis Pelayanan Kesehatan Maternal Dan Neonatal, Jakarta: Bina Pustaka 
FAKTOR RISIKO UMUR, GRAVIDA, STATUS GIZI DAN KEHAMILAN GANDA DENGAN

KEJADIAN HIPEREMESIS GRAVIDARUM (STUDI KASUS KONTROL DI RSUD ACEH TAMIANG)
Mailinda Purwanti, et.al. 